\title{
Artigo \\ Museus indígenas na Costa Noroeste do Canadá e nos Estados Unidos: \\ colaboração, colecionamento \\ e autorrepresentação
}

\author{
Andrea Roca ${ }^{1}$ \\ Universidade Federal do Rio de Janeiro
}

RESUMO: A revisão das relações históricas de dominação nos museus etnográficos e o aparecimento e proliferação dos museus indígenas se enquadram dentro da virada pós-colonialista das últimas décadas. Enquanto os primeiros se reconheceram como instrumentos de legitimação da expansão colonial e começaram a considerar a presença dos produtores dos objetos expostos, os segundos foram aparecendo para reclamar as soberanias indígenas sobre a definição e interpretação de suas próprias histórias. Nesse processo de descolonização museológica, uma das práticas cruciais é o chamado "trabalho colaborativo" entre os profissionais que trabalham nos museus e os índios. A partir da leitura de uma série de trabalhos e exposições na Costa Noroeste do Canadá e nos Estados Unidos onde a colaboração aparece invocada, este trabalho propõe avaliar os alcances, limites e pontos de contato entre o trabalho colaborativo e a autorrepresentação indígena, fornecendo uma estrutura analítica que vai além das fronteiras desses dois países.

PALAVRAS-CHAVE: Museus indígenas, descolonização, trabalho colaborativo, colecionamento, autorrepresentação. 
Você não pode exercer controle sobre outra pessoa on outro grupo a menos que você pense que eles são inferiores e que você próprio é superior. No começo dessa exposição, perguntamos qual era a imagem que você tinha dos indigenas, mas o que realmente estávamos perguntando era como você se vê a si próprio. ${ }^{2}$

\section{Introdução: Indígenas e museus na América do Norte}

As críticas radicais elaboradas pela antropologia do colonialismo permitiram examinar o papel social dos museus etnográficos, colocando-os como parte de um conjunto de tecnologias de dominação e como instrumento de legitimação da expansão colonial (Asad, 1973). Esses museus também foram lugares privilegiados para analisar a crise de representação que estava no centro da chamada crítica pós-moderna. Autoridade, intervenção e "alegorias dos Outros" foram identificadas no armado de mostras e narrativas. A polifonia - uma das estratégias invocadas por essa corrente - apareceu nas salas dos museus etnográficos, "dando voz" aos produtores dos objetos expostos e questionando, simultaneamente, a autoridade, a representatividade e o poder daqueles que organizavam as mostras (Clifford, 1995, 1997b; Karp \& Lavine, 1991; Ames, 1992; de L'Estoile, 2007; Phillips, 2012a, 2012b). Invertendo relações históricas de dominação, essas mudanças permitiam a criação de uma nova museologia que, desconstruindo e abandonando formas tradicionais e aristocráticas de exposição, abria espaço nos museus para a agência e a autorrepresentação indígena.

$\mathrm{Na}$ América do Norte, a reformulação dos museus etnográficos e o aparecimento e multiplicação dos "museus tribais" - assim chamados pela literatura especializada acompanhavam também as mudanças sociais e políticas acontecidas nessa região nas últimas cinco décadas ${ }^{3}$. Esses espaços de memória tornaram-se mais um bastião de luta pelos direitos dos povos indígenas. Segundo James Clifford (1997a: 121), enquanto as grandes instituições museológicas tradicionais - geralmente definidas como "museus dominantes" - articulam uma cultura cosmopolita, ciência, arte e humanismo, muitas vezes com uma orientação nacional, os "museus tribais", vistos esquematicamente, expressam a cultura local, políticas de oposição, parentesco, etnicidade e tradição ${ }^{4}$. O impulsionamento 
desta "era dos museus indígenas" esteve diretamente relacionado à vivência de uma crescente capacidade de reafirmação da soberania dos índios sobre suas próprias histórias e tradições culturais (Hoerig, 2010: 67) .

A par dos acontecimentos citados anteriormente, nos Estados Unidos houve um tratado fundamental que contribuiu ativamente para a apropriação indígena do espaço museológico: o NAGPRA, Native American Graves Protection and Repatriation Act ("Lei de Proteção e Repatriação de Túmulos de Nativos Americanos”, de 1990). Esse documento surgiu como uma resposta aos numerosos argumentos sobre as ilegalidades e injustiças das apropriações dos acervos indígenas, e representou a pedra de toque nas relações formais entre esses povos e os profissionais vinculados a questões de patrimônio. Entre os índios, o NAGPRA aumentou o desejo de conhecer e administrar suas próprias coleções, para assim poderem reescrever o discurso hegemônico e colocar, no seu lugar, ideologias culturais específicas (Hoerig, 2010; Chan, 2013). O impacto dessa legislação se estendeu até o Canadá (onde não existia nenhum equivalente) e outros países da América Latina.

É necessário salientar que os efeitos da colonização nos atuais territórios dos EUA e Canadá criaram sentimentos compartilhados entre grupos indígenas que hoje pertencem a um ou outro país - geralmente chamados Native Americans nos Estados Unidos e First Nations no Canadá. Dois anos mais tarde (1992), nesse último país seria produzido outro importante tratado que alteraria para sempre o panorama da sua museologia: "Virando a Página: Forjando Novas Parcerias entre Museus e Povos Originários" (Turning the Page: Forging New Partnerships Between Museums and First Peoples) foi um documento produzido através do "Grupo de Trabalho sobre Museus e Povos Originários" (Task Force on Museums and First Peoples) ${ }^{6}$. A maior conquista desse documento foi a de fornecer uma sólida armação moral e política para todas as futuras negociações entre os museus e as First Nations do Canadá. Reconhecendo-se as históricas desigualdades entre ambos, exigiu-se o estabelecimento de parcerias para qualquer classe de projeto relacionado com povos indígenas - incluindo as exposições, as pesquisas e o cuidado sobre as coleções -, enfatizando-se a importância deles falarem por si próprios e a aceitação dos seus conhecimentos como legítimos. Por outro lado, cabe destacar que o contexto das comemorações dos 500 anos da chegada de Colombo constituiu uma potente oportunidade para o fortalecimento de todas essas conquistas indígenas, reforçando a utilização dos museus como sítios de contestação política e de revisão das narrativas hegemônicas (veja-se Phillips, 2012b: 205-227). 
Um dos pontos cruciais na agenda dessa nova museologia que foi se construindo é o chamado "trabalho colaborativo" entre os profissionais que trabalham nos museus e os membros das comunidades, tanto nos museus etnográficos quanto nos museus indígenas. No geral, as práticas de colecionamento e curadoria nesses espaços aparecem ligadas a esse "saber fazer" museológico atual. Ora bem: o que se entende por colaboração? Ser consultado? Participar? Projetar? Fazer? Decidir? De que maneira? Por quanto tempo? Entre quais pessoas, grupos ou instituições?

Segundo Michael Ames - um dos impulsionadores da nova museologia no Canadá -, a colaboração seria "um realinhamento de poder, conseguido através da redistribuição da autoridade", acrescentando mais adiante que isso significa "aceitar os direitos de participação e os interesses dos parceiros desde o começo, e permitir que os projetos evoluam naturalmente, inclusive se o fazem com lentidão ${ }^{7}$, procurando uma participação contínua" (Ames, 1999: 45;49). Concordando com esse autor, Ruth Phillips argumenta que "dessa maneira, as relações sujeito/objeto construídas pelas exposições colaborativas se distanciam do monologismo do passado para uma estrutura dialógica" (Phillips, 2012a: 192). Poder-se-ia afirmar que a colaboração estaria diretamente vinculada à famosa definição de Clifford sobre os museus como zonas de contato. Diferentes níveis de autoridade discursiva entre índios e não índios criariam um intercâmbio recíproco de conhecimentos e múltiplos pontos de vista. Os museus se tornam zonas de contato quando "suas estruturas organizativas, como um todo, se transformam numa relação moral, histórica e política em curso; um conjunto de trocas carregadas de poder, um constante empurrar e puxar" (Clifford, 1997b: 192).

A importância da colaboração parece ser apontada principalmente a partir de um certo modelo de divisão do trabalho: os museus dominantes possuiriam as maiores coleções sobre cultura material indígena, enquanto as comunidades exerceriam o saber necessário sobre essas coleções para uma interpretação cultural (Salvador, 1994; Hoerig, 2010) $)^{8}$. O trabalho colaborativo se tornaria desejável a partir do momento em que garantiria uma troca benéfica para ambas as partes, abrindo canais para o intercâmbio de informações e conhecimentos, e permitindo o desenvolvimento de novos paradigmas museológicos (Kreps, 2009: 199). Os curadores dos museus percebem então que o seu trabalho não é só "curar" - dar cuidado a - os objetos, e sim também o de abordar as relações entre objetos e pessoas (op.cit.: 202). Na procura de uma voz indígena, dá-se importância à quantidade de participantes índios nos projetos, fundamentalmente à presença dos mais velhos (Hoerig, 2010; Chan, 2013). Também aponta-se para o valor das 
trajetórias das parcerias entre instituições, pesquisadores e indígenas (Salvador, 1994; Phillips, 2012a; 2012b), e para a construção de vínculos de confiança entre os parceiros (Ames, 1999: 49). Nesses intercâmbios, o papel do curador seria "ajudar à comunidade a perceber sua própria visão, em vez de impor uma narrativa sobre essa comunidade" (Smith, 2005: 434). Essa divisão do trabalho pareceria se tornar ainda mais nítida quando se fala das novas tecnologias e/ou das exposições virtuais (veja-se por exemplo Srinivasan et al., 2009).

Invocada sob a retórica do trabalho dialógico, a colaboração tem se tornado um lugar comum em alguns museus (Kreps, 2009: 193), passando aliás a ser compreendida como ética metodológica e epistemológica (Ames, 1999; La Salle, 2010; Phillips, 2012a; 2012b) e permitindo, dessa maneira, expiar as culpas do modelo colonial. Coincido com a arqueóloga Marina La Salle (2010: 415) quando aponta que a colaboração é uma prática que vai além da parceria e da igualdade; ela implica também autodeterminação e autorrepresentação, isto é, soberania.

A partir da leitura de uma série de trabalhos sobre coleções, exposições e museus onde a prática colaborativa aparece invocada, comentarei algumas das características dessas colaborações em três museus dominantes e três museus indígenas. Meus comentários sobre eles estão baseados na leitura desses ensaios, e no meu próprio conhecimento de algumas dessas instituições ${ }^{9}$ e suas exposições virtuais. A reunião desses seis museus não constitui uma apresentação exaustiva, mas, baseando-me na metodologia comparativa aplicada por Clifford (1997a), acredito que os casos aqui expostos oferecem diferentes tipos de iniciativas que podem ser compreendidas e sistematizadas como variantes de um campo unificado de representação museológica, e que essa sistematização permite avaliar os pontos de contato entre o trabalho colaborativo e a autorrepresentação indígena ${ }^{10}$.

Assim sendo, na primeira parte deste artigo apresentarei as diferentes modalidades de trabalhos colaborativos desses seis museus para, na segunda parte, avaliar os alcances e os limites da colaboração no traçado da autorrepresentação e da soberania dos povos indígenas. Certamente, as questões que essas práticas levantam não podem ser exploradas profundamente em um único artigo, mas, ao expor parte daquilo que se escreve sobre a colaboração, e comparar as maneiras em que ela parece ser compreendida, espero fornecer uma produtiva estrutura analítica para pensarmos a autorrepresentação indígena nas coleções e nos museus, muito além das fronteiras do Canadá e dos Estados Unidos (doravante, EUA). 


\section{I - O trabalho colaborativo como arena política: museus sobre índios, ou museus de e para índios? ${ }^{11}$}

a) Com o Capitólio como tela de fundo e financiado em sua maior parte pelo Congresso dos EUA (Smith, 2005: 433), o National Museum of the American Indian - Smithsonian Institution (doravante, NMAI; Washington DC, EUA) foi criado em 1989 e aberto em 2004. É o primeiro museu nacional desse país dedicado à preservação, estudo e exposição da vida, linguagens, literatura, história e arte dos Native Americans (Smith, 2005: 426-7). É considerado o líder simbólico da interpretação museológica de culturas e povos indígenas (Hoerig, 2010: 66) e coloca o trabalho colaborativo como uma prioridade institucional (Srinivasan et al, 2009: 168; de L'Estoile, 2007: 350-357; Bertolossi, 2010; Phillips, 2012a; 2012b). Tem apoiado a criação de vários museus indígenas ao longo dos EUA, oferecendo também bolsas, treinamentos e seminários neles. Seus 8.000 .000 de objetos - dos quais só expõe 1\% - procuram representar 700 comunidades (Smith, 2005: 428; Hoerig, op. cit.). A mensagem visual é a ideia da diversidade (Phillips, 2012b: 220), materializada e estetizada através desses milhares de objetos (Smith, 2005), muitos deles agrupados em função da sua forma e apresentados sem etiquetas, de maneira a destacar a variedade e as diferenças.

As mostras permanentes desse museu envolvem um alto grau de curadoria e participação indígena (de L’Estoile, op. cit.; Bertolossi, 2010; Phillips, 2012b: 205-227); no entanto, e como aponta Hoerig, o NMAI teria duas falhas importantes (e compartilhadas com os museus não nativos que interpretam comunidades nativas): a primeira é que é praticamente impossível oferecer uma interpretação cultural sobre as 700 comunidades que pretende representar (muitas delas sentindo-se desapontadas; veja-se Smith, 2005); a segunda é que o NMAI não seria um museu para índios, mas sim sobre índios, sublinhando que sua audiência principal não é indígena (Hoerig, 2010: 66-67). Por outro lado, o museu tem recebido críticas (tanto por parte de indígenas quanto de não indígenas) pelo fato de não empreender suficientemente a tarefa de desmascarar o colonialismo, exigindo-se-lhe ao mesmo tempo um maior papel político (Smith, 2005: 432-3), o que sugere a necessidade de outros níveis de colaboração e a produção de outros discursos museológicos ${ }^{12}$.

No entanto, o espaço virtual do NMAI parece oferecer um profundo contraste. É o caso da exposição "Reserva X: O poder do lugar" (Reservation X: The Power of Place) ${ }^{13}$. Curada por First Nations, esta mostra explora a lógica da colonização no estabelecimento das reservas indígenas através do trabalho contemporâneo de 7 artistas índios de New México 
(EUA) e da Costa Noroeste do Canadá. Trabalhando a noção de encarceramento colonial e abordando a instalação de fronteiras raciais e a regulação dos contatos entre "selvagens e civilizados", Reservation X estabelece ao mesmo tempo conhecimentos e epistemologias indígenas sobre vida comunitária, parentesco e meio-ambiente, dando conta de transformações sociais e políticas e ressignificando a história da colonização (veja-se Emberley, 2006: 403-409).

b) O Museum of Anthropology of the University of British Columbia (doravante, MoA; Vancouver, Canadá) foi criado em 1947 e reaberto no prédio atual em 1976. Localizado em território dos índios Musqueam, os esforços desse museu parecem estar dirigidos para a dimensão estética dos objetos indígenas ${ }^{14}$, acompanhando ao mesmo tempo a ênfase no valor do pluralismo cultural pregoado em todas as salas do museu. Considerado como o líder da nova museologia (em certa forma institucionalizada através do paradigmático trabalho de Michael Ames, Cannibal Tours and Glass Boxes, 1992), também coloca a prática do trabalho colaborativo como prioridade institucional (Clifford, 1999: 154; Phillips, 2012a, Srinivasan et al, 2009: 168). Deve-se considerar que, como um dos resultados do Task Force mencionado anteriormente -, a University of British Columbia exige, desde 1992, que todos os pedidos de bolsas e/ou fundos solicitados pelo MoA às agências de governo devem ser realizados com a aprovação e a participação das First Nations. Para Ames (1999: 44; 49), isso transforma os indígenas em sponsors, razão suficiente para possuir o direito de participar em todas as decisões; para Phillips (2012a: 190), tratar-se-ia de um princípio ético chave, dado que ambas as partes contam então com a capacidade de definir e obter todos os benefícios que considerem apropriados.

Apesar de ser citado como modelo de parcerias com as comunidades indígenas (Herle, 1994: 46; Hoerig, 2010: 70), a meu ver o MoA apresentaria contradições significativas entre a estetização e a falta de informação desses objetos nas mostras permanentes, por um lado, e as formas de ser do museu, por outro: seu espaço está aberto para os indígenas estudarem, classificarem e objetificarem seus objetos e coleções; as First Nations têm um papel ativo nos programas educativos do museu, e artistas nativos participam no desenvolvimento das apresentações interpretativas. O MoA tem ainda sido um agente importante no chamado "renascimento" da arte da Costa Noroeste (Herle, 1994: 47).

Mas são as exposições temporárias as que parecem oferecer perspectivas mais amplamente informadas. A mostra "A Fala da Memória: Imagens e Vozes da Escola 
Residencial São Miguel" (Speaking to Memory: Images and Voices from St. Michael's Indian Residential School, em cartaz de setembro de 2013 até maio de 2014) foi baseada na documentação fotográfica reunida por uma sobrevivente dessa escola, e assessorada pelo pessoal Kwakiutl do U'mista Cultural Centre. A escola St. Michael funcionou de 1929 até 1974. Fez parte do conjunto das 140 escolas residenciais espalhadas por todo o Canadá, e que só deixaram de funcionar em 1996. Encarregadas de eliminar o "problema indígena", as crianças eram arrancadas das suas famílias para, nessas escolas, abandonarem suas culturas e tradições e serem educadas no cristianismo, aprenderem o inglês ou o francês como única língua, e acabarem "assimiladas" dentro da civilizada identidade canadense.

No seu conhecido artigo sobre quatro museus da Costa Noroeste, Clifford (1997a) tinha apontado para o caráter mais flexível das mostras temporárias no MoA, assim como nas atividades de arquivo, pesquisa e difusão desse museu, encontrando em todos esses espaços e práticas uma tendência a multiplicar estratégias interpretativas explícitas. Apesar de ter sido uma exposição muito pequena, Speaking to Memory teve um objetivo claramente definido e conseguia criar horror e indignação perante a política indigenista canadense (quase desconhecida pelo público não índio, tanto canadense quanto estrangeiro).

Em outro nível, também é preciso destacar o compromisso estabelecido pelo MoA com os povos indígenas através da "Rede de Pesquisa Recíproca" (Reciprocal Research Network). Criada em 2008 em parceria com algumas First Nations ${ }^{15}$, até o momento este site reúne, on-line, os acervos de 22 instituições "para facilitar a pesquisa recíproca e colaborativa sobre o patrimônio cultural da Costa Noroeste da Colúmbia Britânica" (veja-se http://www.rrncommunity.org/).

c) O Canadian Museum of Civilization (Ottawa, Canadá) foi criado originalmente em 1856 e reinaugurado no prédio atual em 1989. Estabelece um paralelo interessante com o NMAI: das janelas do seu Grand Hall pode-se ver o imponente prédio do Parlamento em Ottawa. Nesse hall encontra-se a maior coleção do mundo de totem poles junto a uma reconstrução de casas indígenas, construídas por artesãos e artistas nativos das seis áreas representadas (Herle, 1994: 49).

Apesar dessa estreita colaboração, Julia Emberley (2006) argumenta que o discurso do museu acabava colonizando o espaço indígena, desterritorializando-o mais uma vez. Essas casas tinham sido erguidas dentro das reservas, regulando os espaços índios dentro da nação canadense. Os valores implicados nesse novo modo de vida foram colocados pela normatividade do Indian Act de 1876, definindo a cotidianidade indígena em todos os 
detalhes (principalmente a submissão das mulheres, dado que a estratégia colonial foi pôr fim ao poder maternal, criando vínculos e cumplicidades entre o poder patriarcal dos índios e o poder colonial). No Canadá, o sistema de reservas foi estabelecido pelo Enfranchisement Act em 1869. Mais tarde, o famoso Indian Act de 1876 regulou o significado da vida nas reservas e definiu o status dos índios (Emberley, 2006: 400) ${ }^{16}$, imbricando-se em todos os aspectos das suas vidas. As mulheres ganharam os mesmos direitos que os homens (quanto à propriedade e herança) só através do chamado Bill C-31 em 1984, alterando-se o status estabelecido até então pelo Indian Act.

Os conflitos criados pelo Indian Act em torno das casas, das famílias e das reservas - espaços onde os índios eram obrigados a se sentir "em casa" - não aparecem nesse Grand Hall, e sim uma harmonia que estaria silenciando o passado e, principalmente, as terríveis condições da moradia indígena no presente. Por sua vez, Phillips (2012b: 210) comenta que a primeira impressão que produzem essas casas é a de um "presente etnográfico" congelado no tempo; no entanto, ela argumenta que isso é convergente com um dos objetivos indígenas desta exposição, que era representar suas próprias culturas como tradicionais e vivas ao mesmo tempo.

d) O Makah Cultural and Research Center (Neah Bay, estado de Washington, EUA) foi inaugurado em 1979. É administrado pelos próprios Makah, trabalhando conjuntamente com a comunidade acadêmica e museológica. Foi criado por iniciativa desse povo depois de se terem achado, em 1970 e dentro do próprio território, 55.000 objetos Makah (pré-contato) e 15.000 restos de estruturas. O desenterramento de todo aquele passado criou um profundo sentido de continuidade cultural entre os Makah, e de respeito por parte dos não índios que colaboravam com eles. Durante aproximadamente 11 anos, os Makah estiveram trabalhando também com profissionais índios e não índios do Royal British Columbia Museum (Victoria, Canadá) e da Universidade de Washington. Gerando-se uma fortíssima consciência política sobre o "ser Makah" e sobre a ideia de legado preservando ao mesmo tempo sensibilidades, memórias e emoções em torno das suas próprias histórias -, um dos principais interesses colocados neste acervo foi a criação de futuras gerações de pesquisadores e especialistas Makah. Eles afirmam não querer mais o que definiram como "efeito helicóptero", referindo-se aos pesquisadores que, uma vez colhida a informação sobre eles, levam-na pra fora da comunidade Makah (Bowechop \& Erikson, 2005: 270). 
e) O A:shiwi A:wan Museum and Heritage Center (New Mexico, EUA) foi inaugurado em 1992, depois de quase 30 anos de projetos e negociações. A criação deste museu Zuni também se viu impulsionada pelas escavações arqueológicas iniciadas no fim dos anos 1960, as quais testemunhavam a ocupação ininterrompida do território desde quase 8.000 anos atrás. Para os Zuni, o público não Zuni era estritamente secundário: a missão fundamental do museu estava dirigida a eles próprios, sendo necessário assegurar o interesse das gerações mais jovens no conhecimento Zuni (por Zunis, para Zunis; citado em Isaac, 2005: 7). Esse conhecimento está distribuído entre diferentes sociedades religiosas/esotéricas, derivadas de distintos ancestrais. Nenhum indivíduo tem acesso a todas essas sociedades, estando elas protegidas por "guardiões" e especialistas que cuidam de secretos poderosos, e até perigosos $^{17}$. Conforme essa distribuição, a tarefa do museu não devia ser somente a transmissão de conhecimento: também era necessário controlá-lo hierarquicamente. Assim, por exemplo, a intenção de jovens Zuni de criar registros de áudio sobre antigas preces foram vividas como ameaças pelos mais velhos, interpretando que esses jovens queriam tirar o poder dos seus tutores. Também havia objetos que não podiam ser mostrados, por causa dos seus significados. De acordo com o padrão ocidental da equação visibilidade/conhecimento (onde observar não implica necessariamente "conhecer" o significado), os Zuni foram assessorados para exporem os objetos sagrados, mas sem informar o que eles significavam. Entretanto, uma coisa não se diferenciava da outra para eles, já que os objetos carregam visualidade, significado e poder ao mesmo tempo (veja-se Isaac, 2005).

As negociações, portanto, foram em torno das diferentes expectativas culturais de transmissão de uma tradição de conhecimento através de um museu, institucionalizando esse conhecimento e classificando, ao mesmo tempo, aquilo que seria permitido oferecer ao público geral e aos Zuni ainda não iniciados (Isaac, 2005: 3). Enquanto alguns membros não índios do staff do museu ficavam perdidos com estas questões, os líderes religiosos Zuni e seus quadros hierárquicos foram reforçando seu poder, estabelecendo também níveis de autoridade curatorial em relação ao museu (até chegando a fazer pressão para os pesquisadores não índios do museu não aprenderem a língua Zuni; conforme Isaac, 2005: 4). Na programação da página web, também problematizaram os graus de acessibilidade aos acervos, motivo pelo qual foi necessário criar protocolos de acesso diferenciais (Srinivasan et al., 2009). 
f) U'mista Cultural Centre (Alert Bay, Canadá). Vou me referir mais extensamente a essa instituição, dado que se tornou uma referência no âmbito dos museus indígenas. Sua origem remonta a 1884, quando a Seção 149 do Indian Act determinou o caráter criminoso dos potlatch. Não obstante, estes continuaram se celebrando às costas da polícia. Em dezembro de 1921, o chefe Dan Cranmer ofereceu um importante potlatch durante 6 dias para aproximadamente 400 convidados, vindos de diferentes vilas. A polícia soube da celebração e 45 pessoas foram presas. Foram julgadas em abril de 1922: 22 chefes importantes foram enviados à prisão durante aproximadamente 3 meses, enquanto o resto ficou livre depois de ter sido forçado pela polícia a entregar a parafernália do potlatch, em troca da sua liberdade (Cranmer Webster, 1990, 1995; Saunders, 1995: 40). Os aproximadamente 750 objetos confiscados foram chamados imediatamente de “patrimônio cultural" pelas autoridades (Saunders, 1995: 57); alguns deles foram vendidos, e outros foram enviados para Ottawa ${ }^{18}$. Depois desses procedimentos, o agente a cargo assegurava que o potlatch estava "verdadeiramente morto" (Cranmer Webster, 1995: 138139). Entretanto, esta cerimônia permaneceu na clandestinidade, sendo celebrada em regiões muito distantes e frias para assim desencorajar as perseguições da polícia.

Em 1951 - quase 70 anos depois da promulgação da lei - a Seção 149 do Indian Act foi revogada. A partir desse momento, os Kwakiutl começaram a reclamar a devolução da chamada "coleção do potlatch". Eram completamente conscientes de que a repatriação que estavam pedindo tinha um caráter único: em nenhum outro ponto do Canadá os indígenas tinham sido perseguidos pela lei, nem nenhum outro grupo tinha sido obrigado a entregar seus pertences. Em 1972, o Conselho do National Museums of Canada decidiu o retorno dessas peças, com a condição de que se construísse um museu para poder albergá-las ${ }^{19}$.

O Conselho Kwakiutl decidiu então construir um museu em Cape Mudge (Quadra Island, na costa leste da Ilha de Vancouver). Mas esta decisão foi contestada por Gloria Cranmer Webster, filha do chefe Dan Cranmer (quem tinha oferecido aquele potlatch em $1921)^{20}$. Depois de muitas negociações, foram criados dois museus ${ }^{21}$ : o Kwagiulth Museum and Cultural Center em junho de 1979, e o U'mista em novembro de 1980 (que significa "resgatado do cativeiro"). A divisão da coleção entre esses dois museus foi a expressão contemporânea de rivalidades tradicionais entre linhagens (Jacknis, 1996: 279280), legitimando a herança cultural da família Cranmer (Saunders, 1995: 48). A meu ver, o atual funcionamento dessas rivalidades evidencia, mais ainda, que ambos os museus estão representando a culturas vivas ${ }^{22}$. 
O U'mista fica do lado da antiga St. Michael Indian Residential School, aquela escola residencial que foi objeto da exposição temporária do MoA (comentada na parte "b" deste artigo). É um centro cultural, e não um museu; segundo um dos Kwakiutl fundadores, "os índios não vão aos museus" (Cranmer Webster, 1990: 135) ${ }^{23}$. O objetivo do U'mista é claro: através de uma única exposição permanente, organizada com a coleção recuperada, contase uma história de relações de poder baseada em quatro momentos específicos: a proibição do potlatch, a prisão dos chefes, a confiscação desses objetos e seu retorno. Não há um empenho em dar a conhecer "a cultura" dos Kwakiutl, e sim uma história particular. Tampouco se fala "dos potlatch": só se faz referência a um deles. Os objetos configuram uma exposição aberta e conservam a ordem de aparecimento que têm durante essas cerimônias, começando pelos cobres e as máscaras, em ordem hierárquica; a eles se somam dezenas de cartas, reclamos e matérias de jornal, que contribuem a criar um clima opressivo de exploração, indignação e injustiça. Também há vídeos documentais produzidos pelos Kwakiutl (sobre a proibição do potlatch e a confiscação da coleção) e objetos de artistas contemporâneos.

A história que ali se conta não coincide com a bela imagem democrática do Canadá e seu multiculturalismo. Antes do que estar exposta para ser objeto de fruição estética, a "coleção do potlatch" está aí para que aprendamos sua história e fiquemos indignados e, ao mesmo tempo, para que reconheçamos a integridade e a fortaleza dos Kwakiutl. O U'mista demonstra que a lei antipotlatch falhou, porque não conseguiu nem suspendê-lo, nem acabar com ele; também demonstra que os Kwakiutl não eram uma "raça em extinção" pronta pra ser assimilada e desaparecer (Saunders, 1995). Como aponta Clifford (1999: 141; 172), todas aquelas narrativas de desaparecimento cultural e salvamento puderam ser substituídas por histórias de renascimento e de luta, fazendo, de uma tragédia, uma mensagem de esperança e de orgulho.

Gloria Cranmer Webster - fundadora e primeira diretora do U'mista - aponta que a repatriação da coleção do potlatch é única: enquanto a maioria das demandas de repatriação estão baseadas na ideia de que os objetos são vitais para a saúde espiritual das comunidades, esse não é o caso dos Kwakiutl. Eles não precisam desses objetos e máscaras para os rituais, mas era necessário que fossem devolvidos para retificar a terrível injustiça que faz parte da sua história. Segundo ela, "nós temos usado o retorno dos nossos tesouros como a base para reconstruir e fortalecer a nossa cultura" (Cranmer Webster, 1995: 141). A mostra está composta por valores do presente. O U'mista ensina que a proibição e a confiscação do potlatch não são uma questão indígena: fazem parte da construção do 
Canadá e da história da colonização branca nesse território. Essa mensagem é reforçada através da página web, com informações ainda mais detalhadas (veja-se www.umista.org).

\section{II - Colaboração, colecionamento e autorrepresentação}

A meu ver, os casos aqui apresentados demonstram claramente os principais interesses dos indígenas em torno dos museus: a) a necessidade de substituir representações anteriores, estereotipadas e anacrônicas, para acabar com a imagem de um "outro" - exótico e ahistórico; b) o interesse em produzir conhecimento sobre si próprios; c) a importância das exposições serem projetadas para as próprias comunidades, sentindo-se refletidos e identificados nesses acervos; d) o interesse em criar ambientes de extraordinário aprendizado, produzindo argumentos culturais que permitam manter a integridade dessas comunidades; e) a importância de apresentar objetos arqueológicos ou históricos através de uma interpretação contemporânea que permita dar conta de uma continuidade cultural, colocando os índios na história para, somente assim, poder compreendê-los nos seus presentes (veja-se Roca, 2008); f) interesse em conseguir uma maior comunicação e, fundamentalmente, propagar o ativismo político. Apesar das boas intenções das parcerias colaborativas, estes objetivos parecem ser mais viáveis nos museus indígenas - espaços onde haveria mais possibilidades de introduzir, com maior ênfase, a história e a política, questionando e desafiando as apresentações insuficientes e/ou estetizadas e/ou generalizantes e/ou ambíguas dos museus dominantes.

Isso coloca boas perguntas para o nosso trabalho antropológico. Referindo-se às dificuldades e alcances do trabalho colaborativo, Clifford opina que

Enquanto os museus só se limitem a consultar (muitas vezes depois de se ter
estabelecido com firmeza a visão curatorial), enquanto não aportem uma maior
variedade de experiências históricas e agendas políticas no planejamento atual
das exposições e nas coleções que possuem, serão percebidos como
meramente paternalistas pelas pessoas cujo contato histórico com eles tem se
reduzido à exclusão e à condescendência (Clifford, 1997b: 207-208).

Sem dúvida, um trabalho colaborativo baseado em um profundo compromisso epistemológico e político pode gerar resultados valiosos para ambas as partes. Mas, para isso acontecer, é necessário ir além da colaboração quando entendida como um simples modelo de consulta e considerar a desigualdade latente em muitas dessas parcerias. Além 
de contarem com as coleções, os museus dominantes também possuem o financiamento, a experiência profissional e outro tipo de recursos (estrutura edilícia, tecnologias, publicidade, etc.) (Hoerig, 2010; La Salle, 2010). Pelo fato de essas desigualdades terem estado institucionalizadas durante décadas, muitas vezes é complicado, para os profissionais dos museus, compreender os alcances dessas negociações ${ }^{24}$. Algumas instâncias de pesquisa também ficariam fora da colaboração: a preparação integral dos projetos, a alta especialização necessária (nos EUA e o Canadá) para a obtenção de bolsas e subsídios, e a distribuição dos benefícios obtidos acaba, no geral, nas mãos dos acadêmicos, não nas dos participantes (La Salle, op. cit.: 413). A ausência de reciprocidade nesses intercâmbios correria o risco de favorecer um modelo colonialista extrativo (Hoerig, 2010: 70; La Salle, 2010 $)^{25}$.

Essas desigualdades tornam-se ainda mais problemáticas quando consideramos a natureza temporária dessas colaborações, o que dificultaria a substituição de mensagens e/ou representações anteriores. A exposição (temporária) no MoA sobre as escolas residenciais não teve - nem terá - o peso da sua mostra permanente, com sua magnífica estetização dos totem poles e outros objetos da Costa Noroeste. Mas, como aponta Gloria Cranmer Webster (1990), aos Kwakiutl pouco lhes importa a admiração mundial pela "arte dos totens" quando a grande maioria dos seus jovens convive com as mais altas taxas de suicídio, alcoolismo, drogas e desemprego, com baixos níveis educacionais e de saúde, e com a devastação das suas florestas - entre outros problemas ${ }^{26}$.

No quadro dessas desigualdades, é necessário olharmos com atenção para as supostas "ajudas" ou "guias" que os indígenas precisariam para montar as exposições que falam sobre eles (veja-se por exemplo Smith, 2005). As pretendidas condições de igualdade do trabalho colaborativo implicariam intercâmbios, não "ajudas" nem "guias", justamente porque a colaboração teria como objetivo solucionar o desequilíbrio de poder entre pesquisadores e pesquisados (La Salle, 2010: 402), aceitando que os conhecimentos das comunidades são tão válidos quanto os ocidentais (Phillips, 2012a: 191). A invocação desses termos parece trazer à tona o risco da infantilização do índio, tão recorrente na ordem colonial. Esse risco também aparece vinculado ao tema da repatriação e/ou devolução dos objetos, levantando um velho argumento defendido pelos museus dominantes: os índios não sabem preservar os objetos e/ou não possuem os meios para fazê-lo. Mas, a meu ver, não adianta colocar semelhantes questões sem antes perguntarmos o que seria preservação para os índios; como aponta Kreps (2009: 193), a colaboração e a co-curadoria também permitiriam aceder aos diferentes modos indígenas de percepção, 
interpretação e preservação sobre o que eles reconheceriam e definiriam como patrimônio cultural.

Torna-se necessário, aliás, conhecer os limites desses trabalhos colaborativos. Como sabemos, os acervos e as exposições sobre povos indígenas implicam valores e significados diferentes daqueles dos museus ocidentais. $\mathrm{E}$ os fazeres museológicos (colecionamento, classificação, curadoria, preservação, exposição, propriedade e administração dos resultados das pesquisas, entre muitos outros) nem sempre estão atravessados pelos valores e preocupações desses povos ${ }^{27}$.

É de fundamental importância, portanto, apresentar as condições - sociais, históricas, políticas - em que são estabelecidas essas parcerias. Porque a colaboração, além de ser um princípio norteador que poderia definir a identidade e/ou as políticas de exposição de um determinado museu, é por cima de tudo uma prática extremamente situada, que não se espalha espontaneamente em todas as instâncias do trabalho museológico. De fato, às vezes pode se tornar uma simples retórica que, apelando a um modo de fazer politicamente correto, acabaria sendo mais uma ramificação do discurso neoliberal sobre reconciliação e/ou reparação, sem modificar o status quo da pesquisa antropológica (La Salle, 2010) ${ }^{28}$.

Por outro lado, é importante levar em conta que o fato de os indígenas estarem participando em um espaço onde nunca estiveram antes não é suficiente, per se, para afirmar que nesses "museus colaborativos" as práticas coloniais desapareceram para todo o sempre. Referindo-se ao NMAI, Claire Smith (2005: 426) afirma, por exemplo, que "a simples noção [da existência] de um NMAI, em si mesma, tem o potencial de permitir aos visitantes repensarem a história dos povos nativos e, na medida em que a história é escrita pelos vencedores, [tem o potencial] de estabelecer o triunfo dos povos nativos sobre as adversidades do colonialismo". Traçando um esquema de "vencedores e vencidos", parece-me que essa afirmação simplifica brutalmente a trajetória e a vigência de uma multiplicidade de processos de dominação, lutas e resistências; aliás, esse tipo de afirmações impede que a descolonização museológica possa ser compreendida como um longo processo, que ainda está em marcha.

Poder-se-ia argumentar que nos museus criados e administrados por indígenas as dificuldades e/ou possíveis desequilíbrios gerados pelo trabalho colaborativo estariam ausentes ou minimizados. De fato, há uma inversão nas relações de poder: são eles os que detêm a autoridade, os que organizam o conhecimento sobre si próprios e os que controlam - às vezes inteiramente - a sua própria imagem. Nesses museus, são os índios os 
que definem uma política de identidade para si próprios, questionando os naturalizados procedimentos dos museus coloniais: o direito a classificar, nomear e essencializar grupos humanos.

Os museus indígenas tecem sistemas de conhecimentos e representações que, junto com outros, permitem aos índios se autoidentificarem, assim como se mostrarem perante o Estado nacional e a comunidade internacional, representando performaticamente suas diferenças para outros grupos sociais. São espaços onde suas culturas podem aparecer como algo objetivado (no sentido de "cultura com aspas" apontado por Manuela Carneiro da Cunha [2009], isto é, cultura como autodescrição de grupos sociais que a invocam). No entanto, é necessário salientar que essa aparente "cultura objetivada" nas vitrines dos museus - com a carga essencialista que poderia implicar - é nuançada com as possibilidades, lutas e interesses do presente dos índios. No exercício de construção e administração das suas autorrepresentações culturais - tarefa não isenta de conflitos -, a definição e as formas que elas adquirem é resultado da política identitária de cada povo indígena (veja-se de L'Estoile 2007: 350-357; 2011/2012).

Nesse percurso de descolonização da instituição museológica, poder-se-ia dizer que os indígenas estão em um processo de nation building, traçando "tradicionalismos estratégicos" (Ginsburg, 2007, citado em Srinivasan et al., 2009: 166) e utilizando os museus como espaços ativos de invenção de cultura (Wagner, 1981). Nos EUA e no Canadá, a diversidade existente entre essas instituições reflete as estratégias muito diferentes pelas quais as comunidades ajustaram o conceito (alheio, ocidental) de museu, a partir dos seus valores e suas necessidades (Hoerig, 2010: 68). Os casos aqui apresentados demonstram que não há regras gerais e sim situações particulares a cada grupo, surgindo questões em contextos específicos.

Mas há no entanto uma característica em comum que, a meu ver, fortalece ainda mais estes espaços, e é chave para a autorrepresentação. Esses museus e centros culturais têm nascido a partir de claras propostas políticas, em momentos de forte reorganização e militância. Nessa direção, os objetos são convocados e reunidos para compor um discurso identitário muito preciso, funcionando como diacríticos materiais. Entre os indígenas, o colecionamento orientado exclusivamente para um museu ou um centro cultural próprio é uma prática recente e, para criar esses sítios de reconhecimento, de aprendizado e de luta, eles têm tido que organizar seus próprios acervos. Alguns destes têm "aparecido" (o caso das escavações arqueológicas dos objetos Makah e Zuni), ou têm sido repatriados e/ou recuperados (o caso do Kwagiulth e do U'mista). Entretanto, além dessas instituições 
particulares, podemos afirmar que todas as coleções organizadas pelos indígenas partem de um princípio político. Aqui no Brasil temos, por exemplo, a coleção Os primeiros brasileiros, reunida pelos índios do Nordeste (atualmente conservada no Museu Nacional do Rio de Janeiro), о Миseu Magüta, organizado pelos índios ticunas (Benjamin Constant, Amazônia), a Casa de Memória do Velho Tronco Pankararu (Tacaratu, Pernambuco), o Centro Cultural Tapeba e o Memorial Cacique Perna de Pau, organizado pelos Tapebas no município de Caucaia (CE), a Oca da Memória organizada por Tabajaras e Kalabaça no município de Poranga (CE), o Museu dos Kanindé, organizado por Kanindé no município de Aratuba (CE), o museu e centro de artesanato inteiramente gerenciados pelos Pataxós em Coroa Vermelha no Sul da Bahia, entre outras instituições. Apresentando claras evidências com as quais refutar a suposta "extinção" dos índios do Nordeste, a coleção Os primeiros brasileiros reúne objetos xucurus, fulni-ôs, pankararus, kariri-xocós, tuxás, kiriris, pataxó, pataxó-hã-hã-hães, tupinambás, potiguaras, tapebas, tremembés e tapuias, demonstrando a produção artística contemporânea dos povos indígenas do Nordeste e conectando-a à reafirmação da sua identidade e à luta política desses povos (veja-se Pacheco de Oliveira e Melo Santos, 2015) ${ }^{29}$. Por sua vez, o Museu Magüta - primeiro museu indígena do Brasil, criado em 1991 - foi concebido pelas lideranças do Conselho Geral da Tribo Ticuna (CGTT) como mais uma estratégia para acompanhar suas reivindicações fundiárias e identitárias, existindo até hoje uma estreita relação entre o museu e o projeto político do CGTT (veja-se Pacheco de Oliveira, 2012b; Roca, 2015). Quanto à Casa de Memória do Tronco Velho Pankararu, ela visa o fortalecimento da identidade étnica, tornando-se um instrumento político poderoso como contraponto às imagens e narrativas - estereotipadas e preconceituosas - divulgadas principalmente na Casa de Cultura de Tacaratú, cidade próxima da aldeia onde está localizado este novo espaço de memória (veja-se Mura, 2013).

É importante considerar que as formas de conhecimento elaboradas nos museus indígenas estão orientadas, em primeiro lugar, para eles próprios, visando que os membros dos seus povos aprendam sobre suas histórias e culturas, e sintam orgulho delas. A propriedade do conhecimento por eles produzido, assim como a administração e o controle sobre seus próprios acervos, acionam as capacidades críticas dessas coleções, refutando histórias e historiografias coloniais, e combatendo preconceitos e estigmas (veja-se Roca, 2015). Independentemente das suas origens, todas essas coleções encontradas, procuradas, resgatadas, reunidas - têm sido organizadas sob propósitos definidos: elas deviam e devem servir como base para as interpretações culturais desses povos, materializando e perpetuando suas próprias heranças culturais. Dessa forma, eles 
estão reconhecendo que dentro dos museus (esses espaços tradicionalmente alheios e ocidentais) podem ser criadas as estruturas de conhecimento necessárias para reclamar a soberania sobre a definição e interpretação de suas próprias histórias, tornando-se um locus de educação cultural para a comunidade local e a sociedade em geral (Hoerig, 2010: 67;70) e, também, tornando evidente que a cultura é uma dimensão política que aparece, com muita visibilidade, na arena dos museus (Roca, 2015).

Coincido com Karl Hoerig quando este aponta que as interpretações culturais que acabam sendo significativas para as comunidades só podem vir delas próprias; também coincido com ele quando afirma que, geralmente, isto tem acontecido só nos museus indígenas (op.cit.: 66-67). Assim sendo, podemos afirmar que essas instituições constituem ótimos espaços para a autorrepresentação e o emponderamento, fazendo parte do complexo processo de autodeterminação indígena. Por outro lado, e como aponta Anita Herle (1994: 62), uma mais profunda compreensão da relação entre museus e povos indígenas deve levar em conta o contexto mais amplo dos direitos indígenas de autogoverno, um debate ainda central nas agendas políticas da América do Norte.

Assistindo à inauguração da exposição "Índios, os primeiros brasileiros", um dos chefes potiguaras, ao ver a sala da cultura material, disse comovido: "Tudo isto é prova de que nós existimos". No U’mista, Gloria Cranmer Webster garante "Nós ainda estamos aqui, e estaremos sempre" (Jacknis, 1996: 282). Eles são capazes de fazer semelhantes afirmações porque os acervos que eles reuniram os representam; contam com a capacidade de contar suas histórias, e de estabelecer as continuidades com seus presentes. Os seus objetos estão aí, organizados como veículos através dos quais os índios se encontram a si próprios. As coleções reunidas e organizadas pelos indígenas têm a autorrepresentação como fio condutor. Isso as transforma em um universo de colecionamento por si próprio que, até hoje, carece de abordagem epistemológica. E acredito que essa ausência levanta questões que não podem ser abordadas em um único artigo, merecendo ser objeto de outro exercício analítico.

\footnotetext{
${ }_{1}$ Andrea Roca é doutora em Antropologia Social e pesquisadora do Laboratório de Pesquisas em Etnicidade, Cultura e Desenvolvimento - Museu Nacional, Universidade Federal do Rio de Janeiro (LACED/MN/UFRJ). E-mail: andreacmroca@gmail.com. Este trabalho tem suas origens na palestra apresentada em 21 de novembro de 2013 no Programa de Pós-Graduação em Antropologia Social do Museu Nacional (PPGAS/MN/UFRJ), e fez parte da pesquisa realizada durante o período do meu pós-doutorado Capes/Faperj nessa instituição. Enquadrado dentro do projeto "Museus Indígenas e a Re-Significação de Memórias Étnicas: um diálogo entre coleções etnográficas, o processo de 'Nation Building' e mobilizações políticas
} 
contemporâneas" (coordenado por João Pacheco de Oliveira, e desenvolvido com o apoio do CNPq), um dos objetivos da pesquisa foi estabelecer uma análise comparativa entre as estratégias político-museológicas exercidas pelos índios pankararus do Nordeste brasileiro, e aquelas desenvolvidas por algumas comunidades indígenas da Costa Noroeste do Canadá, consideradas pioneiras em iniciativas museológicas.

2 Texto do último painel da exposição Fluffs and Feathers (Penas e Plumas) realizada em 1992 no Woodland Cultural Centre, na cidade de Brantford (província de Ontário, Canadá; citado em Herle, 1994: 61). Todas as traduções do inglês para português, citadas neste artigo, são minhas.

3 Entre essas mudanças, podemos salientar a American Indian Chicago Conference (1961) e o ativismo desenvolvido através da American Indian Civil Rights (1968) junto às agitações do movimento hippie e dos protestos contra a guerra do Vietnam. No Canadá, enquanto a população se solidarizava com os protestos políticos que tinham lugar nos EUA, o Partido Liberal de Pierre Trudeau defendia a "democracia participativa" e a política do multiculturalismo (vejam-se Chan 2013; Hoerig 2010; Srinivasan et al., 2009). A par desses movimentos, na década de 1960, os indígenas da Costa Noroeste foram os protagonistas de um renascimento cultural, colocando suas produções materiais contemporâneas no mercado das "belas artes" (veja-se Saunders, 1995: 38; Jacknis, 1996: 278-9; Townsend-Gault, Kramer and Ki-Ke-In, 2013). Em 1982, a Constituição do Canadá reconheceu a soberania indígena, provocando grandes avanços em torno dos reclamos de terras (Phillips, 2012: 213) e tornando-os visíveis também na arena dos museus.

${ }^{4}$ Dada a conotação pejorativa que o termo "tribal" tem na antropologia de língua portuguesa, referir-me-ei a eles como museus indígenas.

${ }^{5}$ Até 2010, nos EUA havia 236 museus indígenas (Hoerig, 2010: 72); neles participam mais de 100 reservas e comunidades indígenas urbanas (Bowechop \& Erikson, 2005: 264). No Canadá, a província da Colúmbia Britânica (isto é, a região da Costa Noroeste) conta com 286 museus no total, mas a página da Canadian Museum Association não possui uma única classificação para os museus indígenas, aparecendo incluídos dentro de outras categorias institucionais (tais como Human History, Archaeology ou Anthropology, por exemplo).

${ }^{6}$ Este grupo surgiu como resultado do boicote e das discussões ocasionadas em torno da exposição The Spirit Sings: Artistic Traditions of Canada's First Peoples (O Espírito Canta: Tradições Artísticas dos Povos Originários no Canadá), inaugurada em 1988 no contexto dos Jogos Olímpicos de Inverno no Glenbow Museum da cidade de Calgary (província de Alberta, Canadá). O problema não foi propriamente o conteúdo da exposição, mas sim o seu sponsor: a companhia petroleira Shell Oil, que estava em pleno conflito com o povo indígena Lubicon Cree pela extração de petróleo nas terras reclamadas por este. O Grupo de Trabalho teve 25 membros, tanto indígenas como profissionais dos museus.

7 Referindo-se especificamente a duas exposições que foram inauguradas dois anos mais tarde do que o previsto, Ames (1999: 47-48) considera que nas parcerias colaborativas o problema mais difícil de resolver é a questão do tempo necessário para as negociações.

${ }^{8}$ Clifford chama a atenção para o afiado comentário de um Kwakiutl sobre o Museu de Antropologia da Universidade da Colúmbia Britânica, em Vancouver: "Lá têm muito material, mas não sabem muito acerca dele" (Clifford, 1997a: 122).

${ }_{9}$ O Museu de Antropologia da Universidade da Colúmbia Britânica, em Vancouver, e o U'mista Cultural Centre em Alert Bay, ambos na província da Colúmbia Britânica, Canadá.

${ }^{10}$ No quadro geral da minha pesquisa, comentada anteriormente, essas leituras fizeram parte da análise das estratégias políticas aplicadas em coleções e museus por alguns povos indígenas da Costa Noroeste do Canadá. A escolha deste país junto com os EUA se deve, em primeiro lugar, ao caráter pioneiro da institucionalização das práticas colaborativas nos seus museus; em segundo lugar, devido a uma certa simultaneidade na ocorrência - e repercussão - dos seus respectivos eventos político-museológicos, assim como à existência de uma comunicação muito fluente entre os povos indígenas de ambos os países, nomeadamente no que concerne às apropriações e usos das instituições museológicas. Por sua vez, a escolha desses seis museus deriva de critérios que consideraram o maior volume de discussões em torno das práticas colaborativas. 
${ }^{11}$ Essa diferenciação é estabelecida por Lujan (2005), citada em Hoerig (2010: 66).

12 Em sua dissertação de mestrado sobre o papel do NMAI enquanto congregação de diferentes "Nós", Leonardo Bertolossi também aponta para essa polêmica, embora - a meu ver - com um certo tom triunfalista (veja-se Bertolossi, 2010: 186-198).

13 http://nmai.si.edu/exhibitions/reservation_x/intro.htm. Consultado em 03/09/2013.

${ }^{14}$ Essa ênfase na dimensão estética dos objetos já tinha sido apontada por Clifford (1997a: 107-146).

${ }^{15}$ Musqueam Indian Band, Stó:lo Nation/Tribal Council e a U'mista Cultural Society.

16 Os indígenas tiveram direito ao voto a partir de 1920, mas em troca deviam renunciar a sua condição indígena. Só a partir de 1960 puderam votar sem riscos, incluindo-se também as mulheres indígenas.

${ }_{17}$ Como bem aponta Isaac (2005), isso questionava a ideia de que o acesso ao conhecimento é per se um bem universal.

18 Trinta e três objetos foram vendidos imediatamente ao colecionista George Heye, e destinados mais tarde para o Museum of American Indian/Heye Foundation em NY. O resto dos objetos foi enviado para Ottawa; ali, o Department of Indian Affairs dividiu a coleção entre o Victoria Memorial Museum (hoje o Canadian Museum of Civilization) e o Royal Ontario Museum, em Toronto.

19 Através das negociações com o Royal Ontario Museum (Toronto), em 1988 conseguiram a devolução das peças; quanto ao NMAI em NY, já devolveram uma série de peças, mas continua à procura de outras que ainda não pôde identificar. Uma das máscaras foi vendida por eles ao British Museum, em 1933.

${ }^{20}$ E bisneta de George Hunt, o Tlingit que foi o principal informante de Franz Boas.

21 Até ambos os museus ficarem prontos, foram criadas duas sociedades culturais que assumiram o estudo das diferentes dimensões de "propriedade" dos objetos resgatados, para assim poderem dividir a coleção.

22 Ira Jacknis (1996: 279-280) definiu essa situação de rivalidade como um "drama social", nos termos de Victor Turner (1957). Depois da crise e da clara reatualização das suas diferenças, atualmente os dois museus mantêm contato um com o outro. Cabe destacar que a inauguração deles foi coincidente com o período de renascença dos artistas da Costa Noroeste (veja-se Saunders, 1995; Jacknis, 1996).

${ }^{23}$ Como apontam Srinivasan et al. (2009: 166), o fato de muitos desses espaços terem sido chamados "centros culturais" evidencia um forte destaque para a dimensão contemporânea da vida dessas comunidades; são espaços de celebração de culturas vivas, não "museus" no sentido mais tradicional do termo.

24 Ames cita o exemplo de um designer do MoA: “...no começo, ele se perguntava que direito tinham [os indígenas] para desafiar suas ideias do design da exposição, dado que ele era um designer reconhecido. Disse-me que, uma vez que ele assumiu que os povos indígenas possuem suas próprias histórias, percebeu que eram eles os que tinham todo o direito de dizer como as coleções deviam ser montadas e interpretadas" (Ames, 1999: 46).

25 Baseada na perspectiva marxista do arqueólogo George Nicholas (da Simon Fraser University, Colúmbia Britânica, Canadá), La Salle (2010) apresenta a estrutura do que ele chamou "colonialismo científico": o pesquisador possui a autoridade e os meios financeiros para aceder a uma comunidade, extrair conhecimentos e/ou artefatos, e produzir publicações que lhe trarão prestígio no funcionamento da economia acadêmica (orientada pelo princípio de "publish or perish") que, por sua vez, permitir-lhe-ão manter seu trabalho. Nesse modelo, a comunidade pesquisada não recebe benefícios e também não possui controle sobre a informação criada sobre ela, gerando-se portanto uma relação de aberta exploração (veja-se também Phillips, 2012: 190).

26 Referindo-se à admiração dos brancos pelos totens e à rejeição sobre os indígenas e seus problemas na vida real, ela conclui que, aparentemente, os totens seriam aceitos e valorizados só quando afastados dos seus lugares de origem (Cranmer Webster, 1990: 132). 
27 O depoimento a seguir ilustra este ponto de uma forma muito simples: "No museu, eu vi um monte de máscaras sagradas cobertas com um plástico. Segundo nós [os índios Navajo] isso está mal. As máscaras precisam respirar porque há energia nelas; para os Navajo, elas estão vivas. Vocês não podem sufocá-las, porque elas vão se zangar no futuro" (Conrad House, índio navajo; citado em Kreps, 2009: 196).

28 A respeito, parece-me adequado trazer aqui esta reflexão de Biolsi \& Zimmerman: “...os sistemas de dominação - entre eles, colonialismo e racismo - têm notáveis capacidades para acalmar e conter resistências, e parecer (pelo menos, em alguma coisa) como não opressivos...” (Biolsi \& Zimmerman, 1997: 6; citado em La Salle, 2010: 417).

29 A exposição "Índios, os primeiros brasileiros" foi inaugurada em dezembro de 2006 no Forte das Cinco Pontas da cidade de Recife, sob a curadoria de João Pacheco de Oliveira. Desde então, tem sido montada nas cidades de Fortaleza, Bahia, Rio de Janeiro, Natal e Córdoba (Argentina). Os conteúdos e a trajetória dessa exposição podem ser consultados em https://pt-br.facebook.com/osprimeirosbrasileiros

\title{
Referências bibliográficas
}

\author{
AMES, Michael
}

1992 Cannibal Tours and Glass Boxes: The Antbropology of Museums. Vancouver, University of British Columbia Press.

1999 "How to Decorate a House: The Re-negotiation of Cultural Representations at the University of British Columbia Museum of Anthropology". Museum Anthropology, 22(3):41-51, American Anthropological Association.

AsAD, Talal

1973 Anthropology \& the Colonial Encounter. Nova York, Humanities Press.

BERTOLOSSI, Leonardo

2010 Diferentes, Iguais: A Pan-Indianidade do National Museum of the American Indian e suas Variações. Rio de Janeiro, dissertação, Museu Nacional/UfrJ.

Bowechop, Janine e Erikson, Patricia Pierce

2005 "Forging Indigenous Methodologies on Cape Flattery. The Makah Museum as

a Center of Collaborative Research". American Indian Quarterly, Winter \& Spring, vol.29, n. 1/2: 263-273.

Carneiro da Cunha, Manuela

2009 “'Cultura' e cultura: conhecimentos tradicionais e direitos intelectuais”. In _. Cultura com aspas e outros ensaios. São Paulo, Cosac Naify, pp. 311-373.

CHAN, Amy E.

2013 “Incorporating Quliaqtuavut (Our Stories): Bering Strait Voices in Recent

Exhibitions”. Museum Anthropology, vol.36, issue 1: 18-32. 
CLIFFORD, James

1995 Dilemas de la cultura. Antropología, literatura y arte en la perspectiva posmoderna. Barcelona, Gedisa.

1997a "Four Northwest Coast Museums: Travel Reflections". In Routes:

Travel and Translation in the Late Twentieth Century. Cambridge, Harvard University Press, pp. 107-146.

1997b "Museum as Contact Zones". In Routes: Travel and Translation in the

Late Twentieth Century. Cambridge, Harvard University Press, pp.188-219.

1999 Itinerarios transculturales. Barcelona, Gedisa.

CrANMER WEBSTER, Gloria

1990 "The U'mista Cultural Centre". The Massachusetts Review, Spring/Summer: 132-144.

1995 “The Potlatch Collection Repatriation". University of British Columbia Law Review. Special Issue: Material Culture in Flux: Law and Policy of Repatriation of Cultural Property, pp.137-41.

De L'Estoile, Benoit

2007 Le Goût des Autres. De l'Exposition coloniale aux A'rts premiers. Paris, Flammarion. 2011/2012 “A experiência do museu é a de se deslocar” [depoimento]. Proa: Revista de Antropologia e Arte, v. 1, n. 3. Disponível em http://www.revistaproa.com.br/03/? page_id=775.

DUFF, Wilson

1997 [1965] The Indian History of British Columbia: The Impact of the White Man. Victoria, Royal British Columbia Museum.

EMBERLEY, Julia

2006 "(un)Housing Aboriginal Possessions in the Virtual Museum: Cultural Practices and Decolonization in civilization.ca and Reservation X". Journal of Visual Culture, vol.5 (3): 387-410.

GINSBURG, Faye

2007 "Rethinking the digital age". Media anthropology network working papers. Disponível em: http://www.media-anthropology.net/ginsburg_digital_age.pdf.

HERLE, Anita

1994 "Museums and First Peoples in Canada". Journal of Museum Ethnography, Museum Ethnographers Group: United Kingdom, n. 6: 39-66. 
HoErig, Karl A.

2010 "From Third Person to First: A Call for Reciprocity Among Non-Native and Native Museums". Museum Antbropology, vol. 33, issue 1: 62-74.

IsAAC, Gwyneira

2005 "Mediating Knowledges: Zuni Negotiations for a Culturally Relevant Museum". Museum Anthropology, vol.28, issue 1: 3-18.

JACKNIS, Ira

1996 "Repatriation as Social Drama: The Kwakiutl Indians of British Columbia, 1922-1980”. American Indian Quarterly, vol.20 (2): 274-286.

KARP, Ivan e LAVINE, Steven D.

1991 Exhibiting Cultures. The Poetics and Politics of Museum Display.

Washington/Londres, Smithsonian Institution Press.

KREPS, Christina

2009 "Indigenous curation, museums, and intangible cultural heritage". In SMITH,

Laurajane e AkAgawa, Natsuko (org.), Intangible Heritage. New York, Routledge, pp. 193-208.

LA SALLE, Marina J.

2010 "Community Collaboration and Other Good Intentions". Archaeologies: Jornal of the World Archaeological Congress, vol.6 (3): 401-422.

LUJAN, James

2005 “A Museum of the Indian, Not for the Indian". American Indian Quarterly, 29 (3-4): 510-516.

Mauzé, Marie

2003 “Two Kwakwaka'wakw Museums: Heritage and Politics”. Ethnohistory, 50 (3): 503-522.

MurA, Claudia

2013 “Todo mistério tem dono!” Ritual, política e tradição de conbecimento entre os Pankararu. Rio de Janeiro, Contra Capa.

OSTROWITZ, Judith

2009 "Digital Exhibition and Media Reviews. The Website of the U'mista Cultural Society, Alert Bay, British Columbia, Canada". Museum Anthropology, vol. 32, issue 1: 59-60. 
PACHECO DE Oliveira, João

2012a "O retrato de um menino Bororo: Narrativas sobre o destino dos índios e o horizonte político dos museus". Musas (Iphan), v. 5: 36-59.

2012b “A refundação do Museu Maguta: Etnografia de um Protagonismo Indígena” In MAgalHÃes, Aline Montenegro e BEZERRA, Rafael Zamorano (orgs.), Coleções e colecionadores. A polissemia das práticas. Rio de Janeiro, Museu Histórico Nacional, pp. 201-218.

2013 Los primeros brasileños. Catálogo da exposição. Córdoba, Lotería de Córdoba.

Pacheco de Oliveira, João e Santos, Rita de Cássia Melo

2015 "Descolonizando a ilusão museal - etnografia de uma proposta expositiva". Artigo para o dossiê "Coleções Etnográficas e Patrimônio Indígena"'” do Boletim do Museu Paraense Emílio Goeldi - Ciências Humanas. No prelo.

PHILLIPS, Ruth

2012a "Toward a Dialogic Paradigm. New Models of Collaborative Curatorial Practice". In Museum Pieces. Toward the Indigenization of Canadian Museums. Montreal/Kingston: McGill-Queen's University Press, pp.185-204.

2012b "Inside-Out and Outside-In. Re-presenting Native North America at the Canadian Museum of Civilization and the National Museum of the American Indian (2003-2004)". In Museum Pieces. Toward the Indigenization of Canadian Museums. Montreal \& Kingston:McGill-Queen's University Press, pp.205-226.

RAIBMON, Paige

2005 Authentic Indians. Episodes of Encounter from the Late-Nineteenth-Century Northwest Coast. Durham e Londres: Duke University Press.

RocA, Andrea

2008 Objetos alheios, histórias compartilhadas: os usos do tempo em um museu etnográfico. Rio de Janeiro, DEMU-Iphan.

2015 "Acerca dos processos de indigenização dos museus: uma análise comparativa". Mana. Estudos de Antropologia Social, 21 (1): 123-155.

SALVADOR, Mari Lyn

1994 “The 'Kuna Way': Museum, Exhibitions, and the Politics of Representation of Kuna Art". Museum Anthropology, 18 (3): 48-52.

SAUNDERS, Barbara

1995 “Kwakwaka’wakw Museology”. Cultural Dynamics, 7 (1): 37-68. 
SMITH, Claire

2005 "Decolonising the museum: the National Museum of the American Indian in Washington, DC". Antiquity, n. 79: 424-439.

Srinivasan, Ramesh; Enote, Jim; Becvar, Katherine M. e Boast, Robin 2009 "Critical and reflective uses of new media technologies in tribal museums". Museum Management and Curatorship, vol. 24, n. 2: 161-181.

Townsend-Gault, Charlotte; Kramer, Jennifer e KI-KE-IN (eds.) 2013 Native Art of the Northwest Coast: A History of Changing Ideas. Vancouver, UBC Press.

Turner Strong, Pauline 2005 "Recent Ethnographic Research on North American Indigenous Peoples". Annual Review of Anthropology, 34: 253-268.

TURNER, Victor W.

1957 Schism and Continuity in na African Society: A Study of Ndembu Village Life. Manchester, Manchester University Press.

WAGNER, Roy

1981 The Invention of Culture. Chicago, The University of Chicago Press. 


\title{
Indigenous Museums in the Northwest Coast of Canada and in the United States: collaboration, collecting and self-representation
}

\begin{abstract}
The revision of historical relationships of domination in ethnographic museums and the emergence and proliferation of indigenous museums are both part of the post-colonial turn of recent decades. While ethnographic museums have acknowledged their role as instruments of colonial expansion and started to consider the presence of the producers of the objects on display, indigenous museums initiated on-going claims of indigenous sovereignty over the definition and interpretation of their own histories. In this process of museological decolonization one of the crucial practices is the so called collaborative work between professionals that work in museums and indigenous populations. Departing from a series of cases from Canada and the United States that have collaboration as its corner-stones, this text intends to evaluate the scope, limits and contact points between collaborative work and indigenous self-representation, providing an analytic structure that goes beyond the borders of these two countries.
\end{abstract}

KEYWORDS: Indigenous Museums, Decolonization, Collaborative Work, Collecting, Self-representation.

Recebido em janeiro de 2014. Aceito em dezembro de 2014. 